\title{
Microplastic Contamination of Three Commonly Consumed Seafood Species from Taiwan: A Pilot Study
}

\author{
Jennifer Yee-Shian Chen ${ }^{1}$, Yao-Chang Lee ${ }^{2,3}$ (D) and Bruno A. Walther ${ }^{4, *}$ \\ 1 Graduate Institute of Medical Sciences, Taipei Medical University, 250 Wu-Hsing St., Taipei 110, Taiwan; \\ b614101025@tmu.edu.tw \\ 2 National Synchrotron Radiation Research Center, Life Science Group, Hsinchu 30076, Taiwan; \\ yclee@nsrrc.org.tw \\ 3 Department of Optics and Photonics, National Central University, Chung-Li 32001, Taiwan \\ 4 Alfred-Wegener-Institut Helmholtz-Zentrum für Polar- und Meeresforschung, Am Handelshafen 12, \\ D-27570 Bremerhaven, Germany \\ * Correspondence: bawalther2009@gmail.com
}

Received: 27 September 2020; Accepted: 11 November 2020; Published: 17 November 2020

\begin{abstract}
Microplastics have already been detected in various human foods, especially seafood. This problem should be especially pertinent to the Taiwanese public because a relatively high proportion of people's diet comes from seafood. Therefore, a pilot study of microplastic contamination of seafood products commonly consumed by Taiwanese people is presented. Six batches of three seafood species were examined for the presence of microplastics using FTIR spectroscopy. A total of 107 seafood individuals from three species (hard clam Meretrix lusoria, oyster Crassostrea gigas, Loligo squid Loliginidae spp.) weighing a total of $994 \mathrm{~g}$ yielded a total of 100 microplastic particles consisting of nine different polymer types. The most common polymer types were polypropylene, poly(ethylene:propylene:diene), and polyethylene terephthalate; we also detected six additional, but less common polymer types. A total of $91 \%$ of microplastic particles were fragments that likely originated from fragmented plastic debris which was then consumed by the seafood species; the remaining particles were fibers and a pellet. The mean number of microplastics $\mathrm{kg}^{-1}$ was 87.9 microplastics $\mathrm{kg}^{-1}$ across the three examined species. Given that the Taiwanese public average about $10 \mathrm{~kg}$ of seafood consumption per year, a few thousand microplastic particles are estimated to be annually consumed on average. The methodology of this pilot study can now be used to conduct examinations of more seafood species and samples.
\end{abstract}

Keywords: food security; marine anthropogenic litter; microplastics; plastic pollution; seafood; Taiwan

\section{Introduction}

Aquatic but also terrestrial habitats are increasingly impacted by plastic pollution [1-5]. Global plastic production is increasing exponentially and reached 335 million metric tons in 2016 [6-8]. Of these 335 million tons, approximately $1.4 \%$ to $3.8 \%$ enter the oceans each year [9].

Once in the environment, plastic objects and fragments have numerous negative impacts. For example, they can damage ships, even causing accidents, cause the injury and death of animals, and damage habitats and ecosystems. When macroplastics degrade into meso-, micro-, and nanoplastics, they can directly enter the food chain or indirectly contaminate it because of the leaching of their potentially harmful ingredients [1,4,10-12]. For the purposes of our study, meso-, micro-, and nanoplastics are defined to be the following size categories, respectively: 1 to $<10 \mathrm{~mm}$, 
1 to $<1000 \mu \mathrm{m}$, and $<1 \mu \mathrm{m}$, although different thresholds have been used by various authors [13]. Possible human health impacts of microplastic and nanoplastic pollution are the possibility of internal injury and toxic reactions after ingestion or the indirect contamination of air, food, and water with harmful substances.

Microplastics have already been found in various human foods: beer, drinking water, honey, seafood, sugar, and table salt [14-16]. Ingestion of microplastics has been demonstrated for many marine organisms including zooplankton, bivalves, crustaceans, worms, fish, seabirds, reptiles, and mammals $[15,17]$. Previous studies demonstrated a considerable number of microplastics in examined fish individuals [18-20]. Therefore, most humans around the world now ingest various amounts of microplastic (and likely, also nanoplastic) particles directly via food, especially when consuming fish and seafood [1-4]. Because fish and seafood provide more than four billion people with a substantial proportion of their animal protein intake [21], plastic pollution of fish and seafood leads directly to ingestion of microplastic and nanoplastic particles for billions of people.

While this is now an established fact, we nevertheless need to understand much more about the microplastic contamination of seafood, such as: (1) what species are involved; (2) what is the level and variation of contamination; (3) what polymer types are involved; and (4) what is the regional variation of contamination.

Considering the last aspect, we do not have complete geographic coverage yet. Barboza et al. [15] reviewed studies reporting the occurrence of microplastics in shellfish and fish of commercial interest as food, and they listed only one study from China [22], one study which included fish from Japan and Vietnam [23], and none from the Philippines, Korea, or Taiwan. We thus decided to check for microplastics in seafood commonly purchased by Taiwanese people.

The possible problems associated with plastic contamination should be especially pertinent to the Taiwanese public because a relatively high proportion of people's diet is seafood [24]. Taiwan's coastline is heavily polluted with macroplastics [24] and microplastics [25,26], and the waters surrounding Taiwan are amongst the most plastic-polluted in the world, given our current knowledge [27-30]. While some seafood consumed in Taiwan originates from other parts of the world, there also remains a local fishing fleet which fishes in the waters surrounding Taiwan. To find out if such seafood is contaminated, we conducted a pilot study to examine several seafood products commonly consumed by Taiwanese people for the presence of microplastic particles.

\section{Materials and Methods}

\subsection{Selecting Seafood Species}

Taiwan is a nation state in East Asia consisting of one large island (Taiwan Island) and several much smaller islands and island groups. Its population is approximately 23.5 million people, and it has the 30th highest GDP per capita income in the world, with people consuming much local food, but also food imported from all over the world.

In order to determine what species of seafood are commonly consumed by Taiwanese people, we researched publicly available data in September 2017. We found two relevant sources:

1. Chen and Chen [31] provided a list of fishes, shellfish, and cephalopods commonly consumed in Taiwan (Table 1).

2. Taiwan's Fisheries Agency provided estimates of the production quantity of 12 taxa of seafood in Taiwan in 2016 (Figure S1), all of which are commonly consumed in Taiwan. 
Table 1. Information adopted from Table 1 in Chen and Chen [31], which is based on the Taiwanese Dietary Habit and Food Balance Sheet. Chen and Chen [31] used this list of seafood taxa (specifically, shellfish and cephalopods) to determine the mercury levels within seafood commonly consumed in Taiwan.

\begin{tabular}{cc}
\hline Common Name & Scientific Name \\
\hline Asian/Corbicula clam & Corbicula fluminea \\
Asian hard clam & Meretrix lusoria \\
Pacific oyster & Crassostrea gigas \\
Giant tiger prawn & Penaeus monodon \\
Spear shrimp & Parapenaeus spp. \\
Loligo squid & Loliginidae spp. \\
Cuttlefish & Sepiidae spp. \\
Whiteleg shrimp & Litopenaeus vannamei \\
Bigfin reef squid & Sepioteuthis lessoniana \\
Flower crab & Portunus armatus (formerly pelagicus) \\
Mud crab & Scylla serrata \\
Three-spot swimming crab & Portunus sanguinolentus \\
\hline
\end{tabular}

\subsection{Extracting Microplastics from Seafood Samples}

Based on these two lists of seafood products, we purchased samples of three species, namely the hard clam Meretrix lusoria (Veneridae), the oyster Crassostrea gigas (Ostreidae), and Loligo squids Loliginidae spp. (Table 2), which were randomly chosen from the list of commonly consumed species (Table 1, Figure S1). For each species, we obtained two independent batches (or samples) purchased on different dates and from different sources (Table 2).

All samples were immediately wrapped in aluminum foil to avoid contamination and were then frozen.

We used each individual animal as a whole sample. Therefore, for squids, we simply placed the whole animal in a $10 \%$ potassium hydroxide $(\mathrm{KOH})$ solution. However, for the clams and oysters, we removed all the animal parts from inside the shells and placed all of them into the $\mathrm{KOH}$ solution. The rationale was that people in Taiwan consume the entire animal when they cook it for consumption, so using the whole animal most realistically replicates the exposure to microplastics in real-life situations.

We digested animal samples using an already established laboratory protocol using $\mathrm{KOH}$ solution. Dehaut et al. [17] conducted a comprehensive comparative test of dissolution methods, which overwhelmingly recommended the use of a $10 \% \mathrm{KOH}$ solution because it digested all animal tissues except bones and shells within a sufficiently short duration but did not digest or degrade any of the tested plastic types (except for cellulose acetate), which are most commonly found within seafood. This so-called $1 \mathrm{~b}$ protocol was therefore adjudged to be superior to five other dissolution protocols.

Nevertheless, we also ran validation trials to further test this method. We used the $1 \mathrm{~b}$ protocol (summarized in Paragraph S1) to run preliminary tests using samples seeded with (1) only microplastic particles and (2) microplastic particles and clean seafood tissue. In each case, we were able to recover the seeded microplastic particles (Paragraph S2). We therefore had high confidence in the use of the $1 \mathrm{~b}$ protocol, which we consequently adopted to extract microplastics found within our seafood samples.

The details of our dissolution and extraction protocol are given in Paragraph S1. This protocol worked entirely satisfactory for all samples. Briefly, clean, microplastic-free water was prepared using a vacuum pump and filter system, and then, the clean water was used to produce the $10 \% \mathrm{KOH}$ solution. After defrosting, each sample was unwrapped and placed immediately into a new vial, which was then filled with the $\mathrm{KOH}$ solution in a clean laboratory environment. Vials were placed into a $50{ }^{\circ} \mathrm{C}$ water bath for $24-48 \mathrm{~h}$ until each sample had been completely digested. 
Table 2. Six batches of seafood purchased from markets and supermarkets in Taiwan from September to December 2017.

\begin{tabular}{|c|c|c|c|c|c|}
\hline ID $^{\text {a }}$ & Common Name & Scientific Name & Source $^{b}$ & No. inds ${ }^{c}$ & $\overline{\text { Mean Weight (grams) }}{ }^{d}$ \\
\hline 1 & Hard clam & Meretrix lusoria & Supermarket (Qigu, Tainan) & 25 & 11.62 \\
\hline 2 & Hard clam & Meretrix lusoria & Fish Market (Budai Township, Chiayi) & 25 & 11.99 \\
\hline 3 & Oyster & Crassostrea gigas & Wuxing Local Market (Dongshi Township, Chiayi) & 27 & 4.45 \\
\hline 4 & Oyster & Crassostrea gigas & Fish Market (Budai Township, Chiayi) & 24 & 4.58 \\
\hline 5 & Loligo squid small & Loliginidae spp. & Wuxing Local Market (Keelung, New Taipei City) & 4 & 14.34 \\
\hline 6 & Loligo squid medium & Loliginidae spp. & Wuxing Local Market (Keelung, New Taipei City) & 2 & 58.05 \\
\hline Total & 3 species & - & 4 markets & 107 & 993.78 \\
\hline
\end{tabular}

a Each seafood batch was assigned a sample ID (1-6). ${ }^{\mathrm{b}}$ The source is the type of market where the seafood was purchased (in brackets, we give the original source which the seller indicated when asked about the origin of the seafood). ${ }^{\mathrm{c}}$ The number of individuals which were digested and examined for microplastics is given. ${ }^{\mathrm{d}}$ The mean weight of these individuals (whole weight, but after removal from shell for clams and oysters, cf. Methods) is given in grams. 
The same vacuum pump and filter system were used to filter each vial's contents separately through a filter paper with a 20-25 $\mu \mathrm{m}$ pore size (Whatman Laboratory Products), which took less than one minute. The filter paper retained any solid particles bigger than its pore size. The filter paper was then immediately placed into a new petri dish, covered with a labelled cover, and sealed with tape. The filter paper in each petri dish was dried at room temperature for one night. Besides using filtered water and aluminum caps, contamination of samples was minimized by always wearing a laboratory suit which does not shed fibers [32].

During the laboratory work described above, we also always conducted three controls:

i) Blank run: Vials were filled with the $\mathrm{KOH}$ solution and subjected to the same procedure as above, but without animal samples in them, and then, the solution was filtered through a new filter paper.

ii) Control water: One flask was filled with $800 \mathrm{~mL}$ of filtered water and the water was sucked through a new filter paper to check for contamination in the water and/or the filter paper [32].

iii) Control air: $800 \mathrm{~mL}$ of filtered water was poured into an open wide mouth bowl and placed directly next to the laboratory equipment so that the water could catch airborne contaminants. At the end of each laboratory run of digesting and filtering one of the seafood products, the water from the bowl was also filtered through a new filter paper.

\subsection{Counting and Identifying Microplastic Particles}

We examined each filter paper (including the three controls) using an Olympus BX53 Stereo Microscope (range of magnification 2-10x). We counted the number of potential microplastic particles which we could visibly detect for each filter paper and categorized them into three main groups based on overall shape using the definitions established by Karami et al. [32]: fibers/filaments (thin, straight, and often cylindrical particles), fragments (jagged and irregular shaped particles which often have an uneven surface), and pellets (rounded particles). All particles were photographed.

We used FTIR spectroscopy to identify whether a particle was plastic or not and to identify the plastic polymer type. Between January and August 2018, we analyzed potential microplastic particles with the attenuated total reflection Fourier-transform infrared (ATR-FTIR) microspectroscopy at the endstation TLS 14A1 of the National Synchrotron Radiation Research Center (NSRRC). This method analyzes the chemical components based on the characteristic IR absorption of functional groups of plastic polymers. The endstation includes an FTIR spectrometer (IFS 66 v/S, Bruker, Ettlingen, Germany) equipped with an IR microscope (Hypersion 3000, Bruker, Ettlingen, Germany), coupled with a single reflection 20× ATR objective, which is an anvil-shaped Ge crystal with $80 \mu \mathrm{m}$ in diameter. The FTIR spectra of each plastic particle collected onto a filter paper were acquired with 512 scans and a resolution of $4 \mathrm{~cm}^{-1}$ in the spectral range of $4000-400 \mathrm{~cm}^{-1}$ by using the endstation of the ATR-FTIR microspectroscopy. We focused the infrared radiation onto the Ge crystal of the ATR objective and contacted each plastic particle for acquiring the FTIR spectrum of individual plastic particle. To ensure an FTIR spectrum free of spectral interference from water and carbon dioxide in the atmosphere, the optical path of the endstation of the ATR-FTIR microspectroscopy was continuously purged with dry nitrogen evaporated from the LN Dewar (XL-100, TAYLOR- WHARTON, Theodore, AL, USA) during each FTIR data acquisition. This equipment has been used for other studies of microplastic pollution before $[25,26]$.

To determine the polymer type of each particle, we compared each particle's spectrum with those stored in a FTIR polymer spectrum library using OMNIC ${ }^{\mathrm{TM}}$ software (OMNIC 9.2, 2012; ThermoFisher Scientific Inc., Waltham, MA, USA), which automatically matches a measured spectrum to a list of reference spectra from many different materials. 


\subsection{Measuring the Size of Microplastic Particles}

While we determined the polymer types of each particle, we measured the sizes of only a subsample of the particles because of time constraints. Due to time constraints, a random sample of 65 out of the 100 particles was chosen, and then, each particle's size was measured with a scale built into the endstation's microscope (Table S3). To measure the size of each particle, the scale built into the microscope was adjusted to measure the maximum dimension of the particle.

The minimum size which we could detect and measure with this setup was $10 \mu \mathrm{m}$; therefore, this study detected only microplastic particles in the size range of 10 to $<1000 \mu \mathrm{m}$ (cf. [13]).

\section{Results}

To obtain our results, we purchased, digested, and examined six batches of three seafood species from two markets and one supermarket (Table 2). A total of 107 seafood individuals weighing a total of $994 \mathrm{~g}$ were examined, among which we detected a total of 100 microplastic particles consisting of nine different polymer types (Table 3 and Table S3). We used these results to calculate estimated microplastic particles per $\mathrm{kg}\left(\mathrm{or} \mathrm{kg}^{-1}\right)$ of fresh seafood tissue and derived estimates of 213.4 and 20.0 microplastics $\mathrm{kg}^{-1}$ for hard clams (mean =116.7), 124.8 and 91.0 microplastics $\mathrm{kg}^{-1}$ for oysters (mean $=107.9$ ), and 34.9 and 43.1 microplastics $\mathrm{kg}^{-1}$ for loligo squids (mean $=39.0$ ), The mean number of microplastics kg-1 across the three species was $\left((116.7+107.9+39.0)\right.$ particles $\left.\mathrm{kg}^{-1}\right) / 3=87.9$ microplastics kg-1 of fresh seafood.

By far the most common polymer type was polypropylene, with 53 out of the total of 100 particles (53\%), followed by poly(ethylene:propylene:diene) (12 particles) and polyethylene terephthalate (11 particles); the remaining six polymer types had seven particles or less (Table 3). Examples of typical spectra for each of the nine identified polymer types are shown in Figure S2. The two most common polymer types were present in all three species, but none of the others were.

The microplastic particles had the following shapes: 8 were fibers ( 3 grey, 2 black, 1 blue, 1 transparent, 1 yellow), 91 were fragments ( 33 blue, 31 green, 9 white, 7 black, 5 transparent, 3 grey, 2 brown, 1 dark blue), and 1 was a transparent pellet. The sizes of the particles were $190.5 \pm 192.4 \mu \mathrm{m}$ (mean \pm St. Dev.; $\mathrm{n}=65$; range 20-800 $\mu \mathrm{m}$ ) with the size distribution being right-handed (Figure 1).

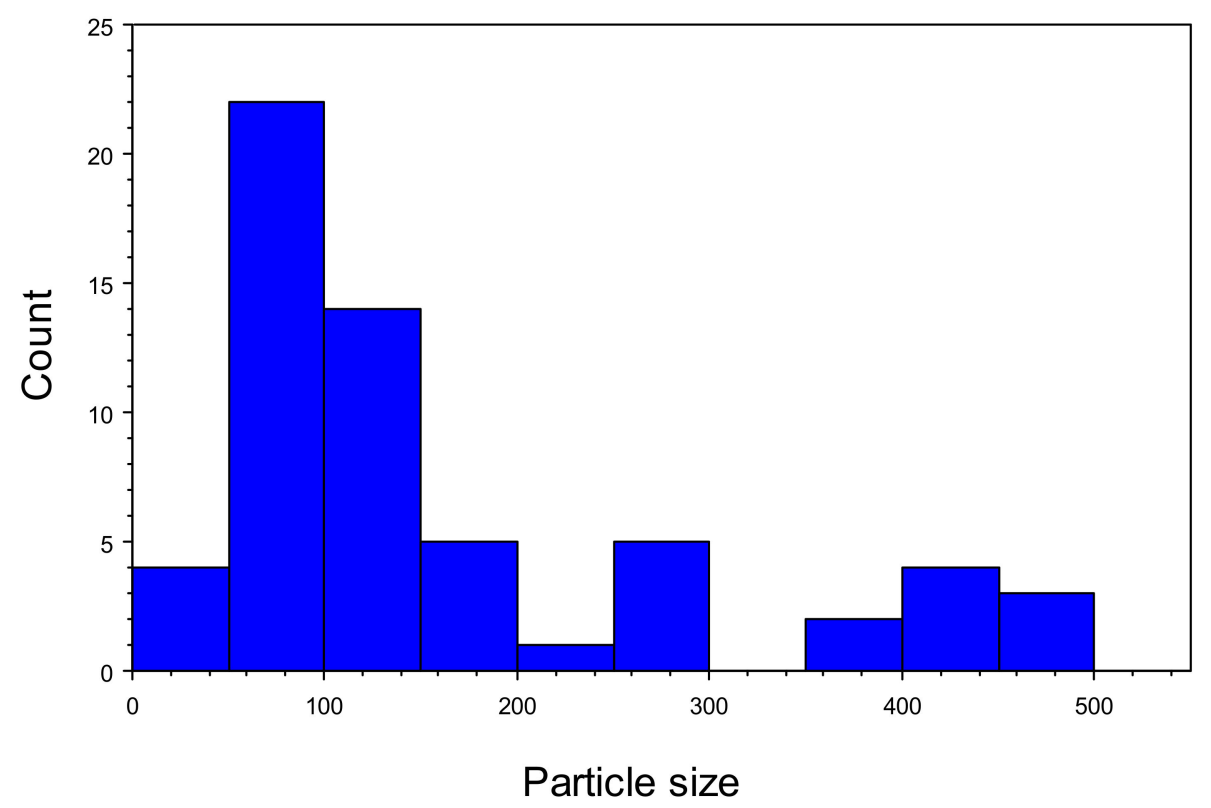

Figure 1. Histogram of the size distribution (in $\mu \mathrm{m}$ ) of the microplastic particles. 
Table 3. Number and polymer type of microplastic particles detected in six batches of seafood.

\begin{tabular}{|c|c|c|c|c|}
\hline ID & Common Name & Total No. ${ }^{a}$ & No. $\mathrm{kg}^{-1 \mathrm{~b}}$ & Polymer Types of Plastic Found (Amount) ${ }^{c}$ \\
\hline 1 & Hard clam & 62 & 213.4 & PP (50), PET (5), PEA (4), PMMA (2), PA (1) \\
\hline 2 & Hard clam & 6 & 20.0 & PP+PE-PP (3), PA (1), PE-LD (1), PET (1) \\
\hline 3 & Oyster & 15 & 124.8 & PA (5), PET (3), PEA (2), EPDM (2), PP (2), PE (1) \\
\hline 4 & Oyster & 10 & 91.0 & EPDM (7), PE-LD (2), PET (1) \\
\hline 5 & Loligo squid small & 2 & 34.9 & $\operatorname{EPDM}(1), \operatorname{PET}(1)$ \\
\hline 6 & Loligo squid medium & 5 & 43.1 & $\operatorname{EPDM}(2), \operatorname{PE}(1), \operatorname{PEA}(1), \operatorname{PP}(1)$ \\
\hline Total & mean across 3 species & $33.3 \pm 31.3^{\mathrm{d}}$ & $87.9^{\mathrm{e}}$ & PP (53), EPDM (12), PET (11), PA (7), PEA (7), PP+PE-PP (3), PE-LD (3), PE (2), PMMA (2) f \\
\hline
\end{tabular}


No microplastic particles were found in our blank, "control air", and "control water" samples. These results strongly suggest that environmental contamination with microplastics did not occur during our laboratory work, but that the microplastics identified by us originated from the seafood products themselves.

\section{Discussion}

We unequivocally demonstrated the microplastic contamination of three species of seafood commonly consumed in Taiwan. The identification of plastic polymers by FTIR spectroscopy is one of the most widely accepted methods to confirm the presence of microplastic contamination; therefore, our results cannot be influenced by possible problems with visual identification [14].

The fact that $91 \%$ of particles were fragments, $8 \%$ were fibers, and $1 \%$ was pellets somewhat reflects the contamination of Taiwan's environment: on sandy beaches, $88.6 \%$ of particles were fragments, $0.2 \%$ were fibers, and $11.2 \%$ were pellets [25], whereby the number of fibers is likely an underestimate because of the sampling method (A. Kunz, pers. commun.). Therefore, the proportions in seafood are roughly similar to the proportions found on sandy beaches (despite the fact that most microplastics recovered from beaches are substantially larger).

The fact that these three types of microplastic shapes had such varied colors suggest that their sources and pathways into seafood were probably also very varied. We assume that most particles originated from the fragmentation of intact plastic debris, which then entered the species when the species fed, as such fragments dominate the microplastic pollution detected around Taiwan $[25,26]$. However, some microplastics may also originate from the manufacturing and packaging processes [14,16,32,33]. In the hard clams, we found 26 blue and 24 green polypropylene fragments (Figure 2), which is $94.3 \%$ of all the polypropylene fragments that we identified (the remaining one and two white polypropylene fragments were found in a squid and oysters, respectively). Many of these fragments had a regular shape, such as cylinders or rectangles, and looked somewhat similar (Figure 2). It is possible that all of these polypropylene fragments originated from some unknown source during the manufacturing or packaging process, as we find it unlikely that hard clams would ingest such similar particles during the growth stage. Likewise, EPDM is a type of synthetic rubber which could possibly originate from conveyor belts during processing (e.g., https://www.exxonmobilchemical. com/en/solutions-by-industry/industrial-applications/conveyor-belts). However, without much more extensive detective work, it remains impossible to establish the exact pathways of how microplastics end up in seafood. Nevertheless, the general pathway from ocean pollution to the inside of fishes and seafood is an obvious and well-established pathway (e.g., [34-36]).
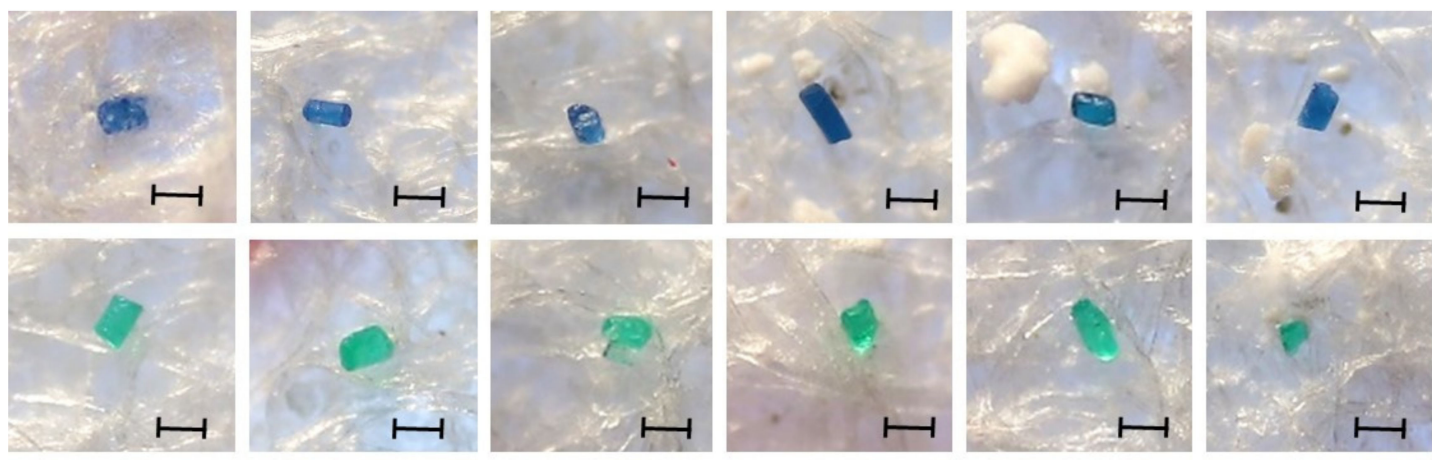

Figure 2. Six examples each of the blue and green polypropylene fragments found in hard clams.

The scale bar indicates $100 \mu \mathrm{m}$.

We detected nine different polymer types, with the most common by far being polypropylene, polyethylene terephthalate, and polyethylene. This result is to be expected because these three types are among the most widely used for packaging and other common uses, and they were the three most abundant types in a global survey of microplastics in table salts [14], while polyethylene and 
polypropylene were the two most abundant types in a global survey of microplastics in the marine environment [37], in a study of Pacific fishes [38], as well as in two studies of microplastics on Taiwan's beaches $[25,26]$. Two of the three remaining types found in our study (namely PA and PMMA) were also detected in table salts [14] and the marine environment [37]. Furthermore, microplastics found in other studies of wild fishes and seafood also included polyethylene [22,34,35], polyethylene terephthalate [22,39], and polypropylene [35], with all three being among the most reported types in a global review [40]. Therefore, the polymer types which mainly contaminated our seafood samples are typical representative of the global plastic pollution problem.

The mean and range of our particles' sizes were also well within the reported range of microplastics in other foods, e.g., Lee et al. [14] reported a range size of 4-7000 $\mu \mathrm{m}$ in their global review.

The microplastic concentrations of hard clams (116.7 microplastics $\mathrm{kg}^{-1}$ ) and oysters (107.9 microplastics $\mathrm{kg}^{-1}$ ) were similar and their ranges overlapped, while the concentrations for squids (39.0 microplastics kg-1) were clearly lower (Table 3). One possible explanation for this result is that clams and oysters are filter feeders and thus, have similar feeding mechanisms that are different from the feeding mechanism of the squids, which are carnivorous predators of various small marine animals. However, controlled laboratory experiments would be needed to establish whether feeding mechanisms are indeed related to rates of microplastic ingestion in these three species.

De Witte et al. [36] found between 260 and 510 microplastics $\mathrm{kg}^{-1}$ in the blue mussel Mytilus edulis, while, for the same species, Van Cauwenberghe et al. [34] reported 200 microplastics $\mathrm{kg}^{-1}$ and Li et al. [39] detected between 900 and 4600 microplastics $\mathrm{kg}^{-1}$. Li et al. [22] examined nine species of commercial bivalves and found between 210 and 1050 microplastics $\mathrm{kg}^{-1}$. For the oyster Crassostrea gigas, Van Cauwenberghe and Janssen [41] reported 470 microplastics $\mathrm{kg}^{-1}$. These levels of contamination are all somewhat higher than ours, but only by a factor of two to four at the lower end. Such differences can be due to real differences in the level of contamination or to different laboratory procedures [14].

The yearly mean consumption of shellfish in Taiwan was $197 \mathrm{~g} /$ week for men and $200 \mathrm{~g} /$ week for women in the 1990s (Table 2 in Chen and Chen [31]). Taking the mean of $198.5 \mathrm{~g} /$ week, this yields an annual consumption of $10.35 \mathrm{~kg} /$ year. Multiplying this estimate with our mean of 87.9 microplastics $\mathrm{kg}^{-1}$ yields an annual intake of about 909.8 microplastics/year. This estimate of shellfish consumption is based on the Nutrition and Health Surveys in Taiwan (NAHSIT) for the period 1993-1996 [42]. A subsequent NAHSIT for the period 2005-2008 found an approximately 35\% increase in the consumption of "fish, seafood and products" [43]. If we assume that the increase was actually $35 \%$ for seafood alone, then the annual consumption would have risen to $14.0 \mathrm{~kg} /$ year and the annual intake to 1230.6 microplastics/year. While the actual numbers may be somewhat different, the general magnitude ( a few thousand microplastic particles) is probably a good preliminary working estimate. In comparison, our numbers are relatively low; e.g., it was estimated that European seafood consumers could be exposed to up to 11,000 microplastic particles per years, and Chinese seafood consumers even to hundreds of thousands of microplastic particles per year [21]. Naturally, further studies need to be conducted, including more species (see Table 1, Figure S1) and more sources from across the country, and a more current estimate of seafood consumption would also be desirable.

To the best of our knowledge, this is the first study published in the scientific literature which demonstrates the presence of microplastics in seafood commonly consumed by Taiwanese people. However, since we began our work in 2017, we have become aware of two other relevant research projects. The first one is a Chinese-language report conducted by Taiwan's Environmental Protection Administration (EPA) [44], which found microplastics in clams, mussels, scallops, and wild and farmed oysters. The second study is an unpublished thesis supervised by National Donghwa University marine biology professor T.-h. Chen; the study found that about $95 \%$ of coral fishes and nearly all 21 turtles had microplastics in their digestive tracts [45], which substantiates many earlier findings of microplastic contamination of ocean-living species (see references above).

Hence, three studies have found substantial numbers of microplastics in various seafood and fish samples from Taiwan and mutually substantiate each other's main findings, including the possible 
effects on human health (see below). The fact that microplastics are found in seafood worldwide has thus also been verified for Taiwanese seafood. Other recent studies also verified the presence of microplastics in table salts purchased in Taiwan [14,16,46].

The possible human health effects of the consumption of microplastics and nanoplastics have been addressed in an increasing number of publications [11,15,21,47-56]. Three possible impacts have been postulated: direct ingestion of microplastics and nanoplastics and possible internal injury; the indirect contamination of air, food, and beverages, including water; and the possibility of microplastics serving as pathogen vectors. Hwang et al. [57] recently demonstrated the potential toxicity of polystyrene microplastic particles at the cellular level. Whether these possible impacts result in actual significant health risks is still largely unknown. GESAMP [56] concluded that "the potential ecological and human health risks of microplastics are relatively new areas of research, and there is currently a large degree of uncertainty surrounding this issue", which is the conclusion largely shared by Miller et al. [55]. Similarly, the EFSA Panel on Contaminants in the Food Chain [54] suggested that microplastics in seafood probably have a small effect on people's overall exposure to additives or contaminants.

Environmental plastic pollution can be alleviated to some extent by cleanup activities [24,58], but much better are source-reduction policies $[27,59,60]$. Therefore, the recently announced future ban of single-use plastic products by the Taiwanese government should be welcomed [27,61,62].

In conclusion, we found that all seafood products from Taiwanese markets contained microplastic particles, although in highly varying amounts (by one order of magnitude). As pointed out above, there is no consensus yet to clarify whether significant health risks exist and what quantity of ingestion of microplastic particles might be considered harmful or not. However, exponentially increasing amounts of plastic are entering into various habitats, whereby this plastic pollution clearly impacts ocean ecosystems the most. Consequently, seafood coming from the ocean is contaminated with microplastics and nanoplastics. Until we know more about the potential health effects, this fact remains worrying, especially given that this impact will increase in the coming decades. In light of our findings, we recommend that the Taiwanese government and its scientific research community continue to monitor and study macroplastic, microplastic, and nanoplastic contamination, and their possible effects on human and animal health.

Supplementary Materials: The following are available online at http://www.mdpi.com/2071-1050/12/22/9543/s1, Paragraphs S1 and S2, Tables S1-S3, Figures S1 and S2.

Author Contributions: Conceptualization, B.A.W.; methodology, J.Y.-S.C. and B.A.W.; laboratory work, J.Y.-S.C. and B.A.W.; FTIR spectroscopy, J.Y.-S.C., Y.-C.L. and B.A.W.; writing-original draft preparation, Y.-C.L. and B.A.W. All authors have read and agreed to the published version of the manuscript.

Funding: This study was financed by a grant entitled "Macroplastic and microplastic pollution in Taiwan's seafood and coastal and river environments" (MOST number 106-2313-B-038 -001) from Taiwan's Ministry of Science and Technology (MOST).

Acknowledgments: We thank Yu-Wen Emily Dai for translations, and Hsiang-Yin Chen, Yu-Wen Emily Dai, Chia-Kwung Fan, Ling-Ling Hwang, and Alexander Kunz for informational input and logistical support. We thank Ching-Iue Chen (infrared beamline manager) and Pei-Yu Huang (FTIR imaging endstation assistant) from the National Synchrotron Radiation Research Center (NSRRC) in Hsinchu (Taiwan) for providing access and assistance with measurements on the FTIR spectrometer. We thank several anonymous reviewers for valuable comments.

Conflicts of Interest: The authors declare that there is no conflict of interests regarding the publication of this paper.

\section{References}

1. Zeng, E.Y. Microplastic Contamination in Aquatic Environments: An Emerging Matter of Environmental Urgency; Elsevier: Amsterdam, Netherlands, 2018.

2. Wagner, M.; Lambert, S. Freshwater Microplastics: Emerging Environmental Contaminants? Springer Open: Berlin, Germany, 2018.

3. Barboza, L.G.A.; Gimenez, B.C.G. Microplastics in the marine environment: Current trends and future perspectives. Mar. Pollut. Bull. 2015, 97, 5-12. [CrossRef] [PubMed]

4. Bergmann, M.; Gutow, L.; Klages, M. Marine Anthropogenic Litter; Springer Open: Berlin, Germany, 2015. 
5. Wang, J.; Peng, J.; Tan, Z.; Gao, Y.; Zhan, Z.; Chen, Q.; Cai, L. Microplastics in the surface sediments from the Beijiang River littoral zone: Composition, abundance, surface textures and interaction with heavy metals. Chemosphere 2017, 171, 248-258. [CrossRef] [PubMed]

6. Geyer, R.; Jambeck, J.R.; Law, K.L. Production, use, and fate of all plastics ever made. Sci. Adv. 2017, 3, e1700782. [CrossRef] [PubMed]

7. PlasticsEurope. World Plastics Production 1950-2015; PlasticsEurope: Wemmel, Belgium, 2016.

8. PlasticsEurope. Plastics-The Facts 2017: An Analysis of European Latest Plastics Production, Demand and Waste Data; PlasticsEurope: Wemmel, Belgium, 2017.

9. Jambeck, J.R.; Geyer, R.; Wilcox, C.; Siegler, T.R.; Perryman, M.; Andrady, A.; Narayan, R.; Law, K.L. Plastic waste inputs from land into the ocean. Science 2015, 347, 768-771. [CrossRef] [PubMed]

10. Krelling, A.P.; Williams, A.T.; Turra, A. Differences in perception and reaction of tourist groups to beach marine debris that can influence a loss of tourism revenue in coastal areas. Mar. Policy 2017, 85, 87-99. [CrossRef]

11. Seltenreich, N. New link in the food chain? Marine plastic pollution and seafood safety. Environ. Health Perspect. 2015, 123, A34-A41. [CrossRef] [PubMed]

12. Wilcox, C.; van Sebille, E.; Hardesty, B.D. Threat of plastic pollution to seabirds is global, pervasive, and increasing. Proc. Natl. Acad. Sci. USA 2015, 112, 11899-11904. [CrossRef]

13. Hartmann, N.B.; Hüffer, T.; Thompson, R.C.; Hassellöv, M.; Verschoor, A.; Daugaard, A.E.; Rist, S.; Karlsson, T.; Brennholt, N.; Cole, M.; et al. Are we speaking the same language? Recommendations for a definition and categorization framework for plastic debris. Environ. Sci. Technol. 2019, 53, 1039-1047. [CrossRef]

14. Lee, H.; Kunz, A.; Shim, W.J.; Walther, B.A. Microplastic contamination of table salts from Taiwan, including a global review. Sci. Rep. 2019, 9, 10145. [CrossRef] [PubMed]

15. Barboza, L.G.A.; Vethaak, A.D.; Lavorante, B.R.; Lundebye, A.-K.; Guilhermino, L. Marine microplastic debris: An emerging issue for food security, food safety and human health. Mar. Pollut. Bull. 2018, 133, 336-348. [CrossRef]

16. Kim, J.-S.; Lee, H.-J.; Kim, S.-K.; Kim, H.-J. Global pattern of microplastics (MPs) in commercial food-grade salts: Sea salt as an indicator of seawater MP pollution. Environ. Sci. Technol. 2018, 52, 12819-12828. [CrossRef] [PubMed]

17. Dehaut, A.; Cassone, A.-L.; Frère, L.; Hermabessiere, L.; Himber, C.; Rinnert, E.; Rivière, G.; Lambert, C.; Soudant, P.; Huvet, A.; et al. Microplastics in seafood: Benchmark protocol for their extraction and characterization. Environ. Pollut. 2016, 215, 223-233. [CrossRef] [PubMed]

18. Boerger, C.M.; Lattin, G.L.; Moore, S.L.; Moore, C.J. Plastic ingestion by planktivorous fishes in the North Pacific Central Gyre. Mar. Pollut. Bull. 2010, 60, 2275-2278. [CrossRef] [PubMed]

19. Foekema, E.M.; De Gruijter, C.; Mergia, M.T.; van Franeker, J.A.; Murk, A.J.; Koelmans, A.A. Plastic in North Sea Fish. Environ. Sci. Technol. 2013, 47, 8818-8824. [CrossRef]

20. Lusher, A.L.; McHugh, M.; Thompson, R.C. Occurrence of microplastics in the gastrointestinal tract of pelagic and demersal fish from the English Channel. Mar. Pollut. Bull. 2013, 67, 94-99. [CrossRef]

21. Wright, S.L.; Kelly, F.J. Plastic and human health: A micro issue? Environ. Sci. Technol. 2017, 51, $6634-6647$. [CrossRef]

22. Li, J.; Yang, D.; Li, L.; Jabeen, K.; Shi, H. Microplastics in commercial bivalves from China. Environ. Pollut. 2015, 207, 190-195. [CrossRef]

23. Karami, A.; Golieskardi, A.; Choo, C.K.; Larat, V.; Karbalaei, S.; Salamatinia, B. Microplastic and mesoplastic contamination in canned sardines and sprats. Sci. Total. Environ. 2018, 612, 1380-1386. [CrossRef]

24. Walther, B.A.; Kunz, A.; Hu, C.-S. Type and quantity of coastal debris pollution in Taiwan: A 12-year nationwide assessment using citizen science data. Mar. Pollut. Bull. 2018, 135, 862-872. [CrossRef]

25. Bancin, L.J.; Walther, B.A.; Lee, Y.-C.; Kunz, A. Two-dimensional distribution and abundance of micro- and mesoplastic pollution in the surface sediment of Xialiao Beach, New Taipei City, Taiwan. Mar. Pollut. Bull. 2019, 140, 75-85. [CrossRef]

26. Kunz, A.; Walther, B.A.; Löwemark, L.; Lee, Y.-C. Distribution and quantity of microplastic on sandy beaches along the northern coast of Taiwan. Mar. Pollut. Bull. 2016, 111, 126-135. [CrossRef] [PubMed] 
27. Walther, B.A.; Kusui, T.; Yen, N.; Hu, C.-S.; Lee, H. Plastic pollution in East Asia: Macroplastics and microplastics in the aquatic environment and mitigation efforts by various actors. In Plastics in the Aquatic Environment_-Current Status and Challenges; Stock, F., Reifferscheid, G., Brennholt, N., Kostianaia, E., Eds.; Springer: Berlin, Germany, 2020.

28. Eriksen, M.; Lebreton, L.C.M.; Carson, H.S.; Thiel, M.; Moore, C.J.; Borerro, J.C.; Galgani, F.; Ryan, P.G.; Reisser, J. Plastic pollution in the world's oceans: More than 5 trillion plastic pieces weighing over 250,000 tons afloat at sea. PLoS ONE 2014, 9, e111913. [CrossRef] [PubMed]

29. Hsiao, S. Microplastics Found in All Waters off Taiwan: Report. Taipei Times. 5 January 2019. Available online: http://www.taipeitimes.com/News/taiwan/archives/2019/01/05/2003707389 (accessed on 1 September 2020).

30. Isobe, A.; Uchida, K.; Tokai, T.; Iwasaki, S. East Asian seas: A hot spot of pelagic microplastics. Mar. Pollut. Bull. 2015, 101, 618-623. [CrossRef] [PubMed]

31. Chen, Y.C.; Chen, M.H. Mercury levels of seafood commonly consumed in Taiwan. J. Food Drug Anal. 2006, 14, 373-378.

32. Karami, A.; Golieskardi, A.; Keong Choo, C.; Larat, V.; Galloway, T.S.; Salamatinia, B. The presence of microplastics in commercial salts from different countries. Sci. Rep. 2017, 7, 46173. [CrossRef]

33. Iñiguez, M.E.; Conesa, J.A.; Fullana, A. Microplastics in Spanish table salt. Sci. Rep. 2017, 7, 8620. [CrossRef]

34. Van Cauwenberghe, L.; Claessens, M.; Vandegehuchte, M.B.; Janssen, C.R. Microplastics are taken up by mussels (Mytilus edulis) and lugworms (Arenicola marina) living in natural habitats. Environ. Pollut. 2015, 199, 10-17. [CrossRef]

35. Neves, D.; Sobral, P.; Ferreira, J.L.; Pereira, T. Ingestion of microplastics by commercial fish off the Portuguese coast. Mar. Pollut. Bull. 2015, 101, 119-126. [CrossRef]

36. De Witte, B.; Devriese, L.; Bekaert, K.; Hoffman, S.; Vandermeersch, G.; Cooreman, K.; Robbens, J. Quality assessment of the blue mussel (Mytilus edulis): Comparison between commercial and wild types. Mar. Pollut. Bull. 2014, 85, 146-155. [CrossRef]

37. Hidalgo-Ruz, V.; Gutow, L.; Thompson, R.C.; Thiel, M. Microplastics in the marine environment: A review of the methods used for identification and quantification. Environ. Sci. Technol. 2012, 46, 3060-3075. [CrossRef]

38. Ghosal, S.; Chen, M.; Wagner, J.; Wang, Z.-M.; Wall, S. Molecular identification of polymers and anthropogenic particles extracted from oceanic water and fish stomach-A Raman micro-spectroscopy study. Environ. Pollut. 2017, 233, 1113-1124. [CrossRef] [PubMed]

39. Li, J.; Qu, X.; Su, L.; Zhang, W.; Yang, D.; Kolandhasamy, P.; Li, D.; Shi, H. Microplastics in mussels along the coastal waters of China. Environ. Pollut. 2016, 214, 177-184. [CrossRef] [PubMed]

40. Li, J.; Lusher, A.; Rotchell, J.M.; Company, S.D.; Turra, A.; Bråte, I.L.N.; Sun, C.; Hossain, M.S.; Li, Q.; Kolandhasamy, P. Using mussel as a global bioindicator of coastal microplastic pollution. Environ. Pollut. 2019, 244, 522-533. [CrossRef] [PubMed]

41. Van Cauwenberghe, L.; Janssen, C.R. Microplastics in bivalves cultured for human consumption. Environ. Pollut. 2014, 193, 65-70. [CrossRef] [PubMed]

42. Wu, S.-J.; Chang, Y.-H.; Fang, C.-W.; Pan, W.-H. Food sources of weight, calories, and three macro-nutrients-NAHSIT 1993-1996. J. Nutr. Sci. 1999, 24, 41-58.

43. Pan, W.-H.; Wu, H.-J.; Yeh, C.-J.; Chuang, S.-Y.; Chang, H.-Y.; Yeh, N.-H.; Hsieh, Y.-T. Diet and health trends in Taiwan: Comparison of two nutrition and health surveys from 1993-1996 and 2005-2008. Asia Pac. J. Clin. Nutr. 2011, 20, 238-250.

44. Environmental Analysis Laboratory (EPA). The Survey for Microplastic in Seawater, Sand, Gravel, and Marine Life Around the Coastal Areas of Taiwan, Penghu, and Mazu Beach (In Chinese); Environmental Analysis Laboratory (EPA): Taoyuan, Taiwan, 2018.

45. Tsai, T.-H.; Hetherington, W. Most Fish Contain Microplastic: Study. Taipei Times. 14 May 2019. Available online: http://www.taipeitimes.com/News/taiwan/archives/2019/05/14/2003715109 (accessed on 1 September 2020).

46. Walther, B. Table Salt with A Pinch of Plastic. Taipei Times. 17 July 2019. Available online: http://www.taipeitimes.com/News/editorials/archives/2019/07/17/2003718804 (accessed on 1 September 2020).

47. WHO. Microplastics in Drinking-Water; World Health Organization: Geneva, Switzerland, 2019.

48. Revel, M.; Châtel, A.; Mouneyrac, C. Micro (nano) plastics: A threat to human health? Curr. Opin. Environ. Sci. Health 2018, 1, 17-23. [CrossRef] 
49. Talsness, C.E.; Andrade, A.J.M.; Kuriyama, S.N.; Taylor, J.A.; vom Saal, F.S. Components of plastic: Experimental studies in animals and relevance for human health. Phil. Trans. R. Soc. Lond. B 2009, 364, 2079-2096. [CrossRef]

50. vom Saal, F.S.; Parmigiani, S.; Palanza, P.L.; Everett, L.G.; Ragaini, R. The plastic world: Sources, amounts, ecological impacts and effects on development, reproduction, brain and behavior in aquatic and terrestrial animals and humans. Environ. Res. 2008, 108, 127-130. [CrossRef]

51. Muncke, J.; Andersson, A.M.; Backhaus, T.; Boucher, J.M.; Almroth, B.C.; Castillo, A.C.; Chevrier, J.; Demeneix, B.A.; Emmanuel, J.A.; Fini, J.B.; et al. Impacts of food contact chemicals on human health: A consensus statement. Environ. Health 2020, 19, 12. [CrossRef]

52. Vethaak, A.D.; Leslie, H.A. Plastic debris is a human health issue. Environ. Sci. Technol. 2016, 50, 6825-6826. [CrossRef] [PubMed]

53. Thompson, R.C.; Moore, C.J.; vom Saal, F.S.; Swan, S.H. Plastics, the environment and human health: Current consensus and future trends. Phil. Trans. R. Soc. Lond. B 2009, 364, 2153-2166. [CrossRef] [PubMed]

54. EFSA Panel on Contaminants in the Food Chain (CONTAM). Presence of microplastics and nanoplastics in food, with particular focus on seafood. EFSA J. 2016, 14, e04501.

55. Miller, K.; Santillo, D.; Johnston, P. Plastics in Seafood-Full Technical Review of the Occurrence, Fate and Effects of Microplastics in Fish and Shellfish; Greenpeace Research Laboratories Technical Report; Greenpeace Research Laboratories: Exeter, UK, 2016.

56. GESAMP. Sources, Fate and Effects of Microplastics in the Marine Environment: A Global Assessment; IMO/FAO/UNESCO-IOC/UNIDO/WMO/IAEA/UN/UNEP/UNDP Joint Group of Experts on the Scientific Aspects of Marine Environmental Protection: London, UK, 2015.

57. Hwang, J.; Choi, D.; Han, S.; Jung, S.Y.; Choi, J.; Hong, J. Potential toxicity of polystyrene microplastic particles. Sci. Rep. 2020, 10, 7391. [CrossRef] [PubMed]

58. Walther, B.A.; Hu, C.-S. How citizen-scientists helped us to document the type and quantity of coastal debris pollution in Taiwan. Mar. Litter News 2018, 10, 24-28.

59. Walther, B. Nation Engulfed by Plastic Tsunami. Taipei Times. 9 January 2015. Available online: http://www.taipeitimes.com/News/editorials/archives/2015/01/09/2003608789 (accessed on 1 September 2020).

60. Walther, B. State Must Act on Plastics Problem. Taipei Times. 4 June 2019. Available online: http://www.taipeitimes.com/News/editorials/archives/2019/06/04/2003716285 (accessed on 1 September 2020).

61. Lin, C.-N. EPA Sets Timetable to Ban Plastic Use. Taipei Times. 14 February 2018. Available online: http://www.taipeitimes.com/News/front/archives/2018/02/14/2003687612 (accessed on 1 September 2020).

62. Leary, K. Taiwan Has Committed to Banning Plastic Items by 2030. World Economic Forum. 26 February 2018. Available online: https://www.weforum.org/agenda/2018/02/taiwan-commits-to-banning-plastic-items-by2030 (accessed on 1 September 2020).

Publisher's Note: MDPI stays neutral with regard to jurisdictional claims in published maps and institutional affiliations.

(C) 2020 by the authors. Licensee MDPI, Basel, Switzerland. This article is an open access article distributed under the terms and conditions of the Creative Commons Attribution (CC BY) license (http://creativecommons.org/licenses/by/4.0/). 